\title{
A revised method for determination of dialkylphosphate levels in human urine by solid-phase extraction and liquid chromatography with tandem mass spectrometry: application to human urine samples from Japanese children
}

\author{
Jun Ueyama Isao Saito $\cdot$ Ayuko Takaishi $\cdot$ Hiroshi Nomura $\cdot$ Mai Inoue $\cdot$ Aya Osaka \\ Yuka Sugiura • Yumi Hayashi - Shinya Wakusawa - Hiroko Ogi - Kimio Inuzuka • \\ Michihiro Kamijima • Takaaki Kondo
}

Received: 17 June 2014/ Accepted: 21 August 2014/Published online: 8 October 2014

(C) The Japanese Society for Hygiene 2014

\begin{abstract}
Objectives Biological monitoring of organophosphorus insecticide (OP) metabolites, specifically dialkylphosphates (DAP) in urine, plays a key role in low-level exposure assessment of OP in individuals. The aims of this study are to develop a simple and sensitive method for determining four urinary DAPs using high-performance liquid chromatography with tandem mass spectrometry (LC-MS/MS), and to assess the concentration range of urinary DAP in Japanese children.

Methods Deuterium-labeled DAPs were used as internal standards. Urinary dimethylphosphate (DMP) and diethylphosphate (DEP), which passed through the solid-phase extraction (SPE) column, and dimethylthiophosphate (DMTP) and diethylthiophosphate (DETP), which were extracted from a SPE column using $2.5 \% \mathrm{NH}_{3}$ water including $50 \%$ acetonitrile, were prepared for separation analysis. The samples were then injected into LC-MS/MS.
\end{abstract}

J. Ueyama $(\bowtie) \cdot$ H. Nomura · M. Inoue · A. Osaka ·

Y. Sugiura · Y. Hayashi · S. Wakusawa · T. Kondo

Department of Pathophysiological Laboratory Sciences, Field of

Radiological and Medical Laboratory Sciences, Nagoya

University Graduate School of Medicine, Nagoya 461-8673,

Japan

e-mail: ueyama.jun@e.mbox.nagoya-u.ac.jp

I. Saito

Food Safety and Quality Research Center, Tokai COOP

Federation, Nagakute, Japan

A. Takaishi $\cdot$ H. Ogi $\cdot$ K. Inuzuka

Okazaki City Public Health Center, Okazaki, Japan

M. Kamijima

Department of Occupational and Environmental Health, Nagoya City University Graduate School of Medical Sciences, Nagoya, Japan
The optimized method was applied to spot urine samples from 3-year-old children (109 males and 116 females) living in Aichi Prefecture in Japan.

Results Results from the validation study demonstrated good within- and between-run precisions $(<10.7 \%)$ with low detection limits ( 0.4 for DMP and DMTP, 0.2 for DEP and $0.1 \mu \mathrm{g} / \mathrm{L}$ for DETP). The geometric mean values and detection rates of the urinary DAPs in Japanese children were $14.4 \mu \mathrm{g} / \mathrm{L}$ and $100 \%$ for DMP, $5.3 \mu \mathrm{g} / \mathrm{L}$ and $98 \%$ for DMTP, $5.5 \mu \mathrm{g} / \mathrm{L}$ and $99 \%$ for DEP, and $0.6 \mu \mathrm{g} / \mathrm{L}$ and $80 \%$ for DETP, respectively.

Conclusions The present high-throughput method is simple and reliable, and can thereby further contribute to development of an exposure assessment of OP. The present study is the first to reveal the DAP concentrations in young Japanese children.

Keywords Organophosphorus insecticide .

Dialkylphosphate · Human urine sample · LC-MS/MS .

Solid-phase extraction

\section{Introduction}

Organophosphorus insecticides (OPs) have been indispensable, thanks to their low cost and beneficial effects on crop yield, forest protection and hygienic management in urban settings, despite the availability of newer insecticides such as pyrethroid and neonicotinoid insecticides [1]. Owing to the improved analytical methodology for urinary OP metabolites, dialkylphosphates (DAPs), they have been measured as a biomarker of OP for assessing not only occupational but low-dose environmental exposure. The measurement of urinary DAPs in epidemiological studies has gained in importance 
since a variety of adverse health effects such as neurologic disorders and thyroid hormone disruption are associated with chronic low-dose exposures to OPs [25]. We have characterized urinary DAP concentrations in the Japanese with a previously used measurement method in three distinct occupational settings, i.e., a general working condition without occupational insecticide exposure, and indoor and outdoor pesticide spraying work conditions [6]. The results showed that urinary DAP concentrations in the general and occupationally OP-exposed populations were approximately at the same or lower levels compared with those measured in their overseas counterparts. The results also indicated that studies of the exposure assessment of OP specific to Japanese populations should be developed due to the diverse characteristics of OP exposure levels among countries. Although many researchers have recently investigated OP exposure risks in children, no basic information regarding urinary DAP concentrations in Japanese children has been available [6-9].

The difficulty in measuring urinary DAP due to its low-level concentration hinders further development of epidemiological studies dealing with the possible toxicity from low-level, long-term OP exposure. Urinary DAP measurement is composed mainly of two procedures, sample preparation steps and separation analysis. Some preparation techniques such as liquid-liquid extraction (LLE), solid-phase extraction (SPE), lyophilization and azeotropic distillation have been reported (Table 1). SPE is superior to other extraction method in terms of its higher selectivity, easier and speedy handling, and reduction of hazardous extraction solvents. Gas chromatography (GC)-mass spectrometry (MS), GC-MS/MS, or high-performance liquid chromatography (LC)-MS/MS have been commonly-used apparatuses for the separation analysis. However, each of these separation techniques has its own merits and demerits. The notable demerits in GC-based methods are labor-intensive and time-consuming derivatization steps, and in LC-based methods, the demerits are relatively poor sensitivities. The drawbacks of the LC-based method can be mitigated when triethylamine (TEA) is used as an ion pair reagent and an ionization accelerator of DAPs [20, 21]. However, TEA has a high possibility of contaminating LC pipes, and thus the measurement in the positive ion mode might be interfered by an intense noise originating from such contamination [21]. To address this issue, the purpose of this study is to establish a simple and sensitive LC-MS/MS method without using TEA, for measurement of urinary DAPs, dimethylphosphate (DMP), diethylphosphate (DEP), dimethylthiophosphate (DMTP), and diethylthiophosphate (DETP), and to evaluate DAP concentrations in urine from Japanese children.
Table 1 Analytical methods for detecting dialkylphosphates in human urine samples

\begin{tabular}{lll}
\hline References & $\begin{array}{l}\text { Sample } \\
\text { preparation }\end{array}$ & $\begin{array}{l}\text { Instruments for } \\
\text { separation analysis }\end{array}$ \\
\hline Nutley et al. [10] & Azeotropic distillation & GC-FPD \\
Aprea et al. [11] & Azeotropic distillation & GC-FPD \\
Moate et al. [12] & SPE & GC-FPD \\
Hardt et al. [13] & LLE & GC-MS \\
Oglobline et al. [14] & Lyophilization & GC-MS/MS \\
Lin et al. [15] & SPE & GC-FPD \\
Brabo et al. [16] & Azeotropic distillation & GC-MS/MS \\
Ueyama et al. [17] & LLE + SPE & GC-MS \\
De Alwis et al. [18] & SPE & GC-MS/MS \\
Dulaurent et al. [19] & LLE & LC-MS/MS \\
Odetokun et al. [20] & SPE & LC-MS/MS \\
\hline
\end{tabular}

$S P E$ solid-phase extraction, $L L E$ liquid-liquid extraction, $G C$ gas chromatography, FPD flame photometric detector, $L C$ liquid chromatography, $M S$ mass spectrometry

\section{Materials and methods}

Chemicals and reagents

DMP tetramethylammonium salt (99.9\%), DMTP ammonium salt (98.9 \%), DEP (98.2 \%), DETP ammonium salt $(95.2 \%)$, DMP sodium salt- $\mathrm{d}_{6}(98.7 \%)$, DMTP potassium salt-d $_{6}(99.0 \%)$, DEP ammonium salt-d $\mathrm{d}_{10}(99.2 \%)$ and DETP potassium salt-d $\mathrm{d}_{10}(98.2 \%)$ were purchased from Hayashi Pure Chemical Ind. (Osaka, Japan). Formic acid, acetonitrile, water, and ammonium formate (each LC-MS grade) were obtained from Sigma-Aldrich (St. Louis, MO, USA). Special grade formic acid and $25 \%$ ammonia solution were purchased from Wako Pure Chemicals (Osaka, Japan) and Sigma-Aldrich, respectively. All other reagents were of analytical grade. The Oasis WAX SPE column (Waters Corporation; Milford, MA, USA), which was packed with polymeric reversed-phase and weak anion exchange mixed-mode sorbent, was used for DAP extraction from urine samples.

\section{Preparation of stock solutions}

Standard DAPs were diluted to a concentration of $1,000 \mathrm{mg} / \mathrm{L}$ in acetonitrile, and further diluted with the same respective solvents to prepare working standard solutions at concentrations ranging from 0.1 to $10 \mathrm{mg} / \mathrm{L}$. Deuterium-labeled DAPs, for use as internal standard (I.S.) substance, were diluted by acetonitrile to a concentration of $30 \mathrm{mg} / \mathrm{L}$ for DMP- $\mathrm{d}_{6}$ and DMTP- $\mathrm{d}_{6}$, and $5 \mathrm{mg} / \mathrm{L}$ for DEP$\mathrm{d}_{10}$ and DETP- $\mathrm{d}_{10}$ (I.S. stock solution). These solutions were stored in the dark at $-30{ }^{\circ} \mathrm{C}$, and were used within 3 months. Urine, collected from three healthy volunteers 
who were neither treated with drugs nor occupationally exposed to chemicals, was used in basic methodological studies such as validation assay, matrix-matched calibration, and quality control. DAP-spiked pooled urine samples were prepared by addition of working standard solution $<1 \%$ volume to the urine.

Sample preparation procedure

A flow chart of the determination procedure for urinary DAPs is shown in Fig. 1. One milliliter of urine was pipetted into a $10-\mathrm{mL}$ screw-top glass test tube, and $1 \mathrm{~mL}$ distilled water, $20 \mu \mathrm{L}$ formic acid $(100 \mathrm{mmol} / \mathrm{L})$ and $20 \mu \mathrm{L}$ I.S. stock solution were added. After gentle shaking, the test tube was incubated at $37{ }^{\circ} \mathrm{C}$ in a water bath for $10 \mathrm{~min}$ to decrease urinary turbidity. Then, the sample was applied to the SPE procedure.

A SPE cartridge packed into a $1-\mathrm{mL}$ solvent reservoir was pre-conditioned with $1 \mathrm{~mL}$ of $2.5 \% \mathrm{NH}_{3}$ and acetonitrile mixture $(1: 1, \mathrm{v} / \mathrm{v})$, followed by wash with $1 \mathrm{~mL}$ formic acid $(1 \mathrm{mmol} / \mathrm{L})$. Then, the conditioned SPE was loaded with a $1.8-\mathrm{mL}$ urine sample (containing distilled water, I.S. solution and formic acid), and placed under vacuum pressure. Passed samples were collected into new plastic tubes. After incubation $\left(4{ }^{\circ} \mathrm{C}\right.$ for $\left.15 \mathrm{~min}\right)$ and centrifugation $\left(10,000 \times g\right.$ for $5 \mathrm{~min}$ at $\left.4{ }^{\circ} \mathrm{C}\right)$, the supernatant was injected into the LC for DMP and DEP measurement. On the other hand, DMTP and DETP were extracted by continuing use of the SPE column through which DMP and DEP passed. After column wash with $1 \mathrm{~mL}$ acetonitrile, DETP and DMTP were eluted by $1 \mathrm{~mL} 2.5 \% \mathrm{NH}_{3}$ and acetonitrile mixture $(1: 1, \mathrm{v} / \mathrm{v})$. The eluate was dried up with a gentle nitrogen stream at $40{ }^{\circ} \mathrm{C}$ and the residue was resolved with $300 \mu \mathrm{L}$ acetonitrile. After 30-min sonication in an ultrasonic bath and centrifugation $(2,000 \times g$ for $5 \mathrm{~min}$ ), the supernatant was injected into the LC for DMTP and DETP measurement.

Chromatography and mass spectrometry conditions

LC-MS/MS analysis was run on an Agilent 1260 Infinity Binary LC system coupled with an Agilent 6430 triple quadrupole mass spectrometer (Agilent Technologies, Inc., Santa Clara, CA, USA). The LC operating conditions were as follows: LC column, Scherzo SM-C18 (Imtakt, Kyoto, Japan), $100 \times 2 \mathrm{~mm}$ i.d., $3 \mu \mathrm{m}$ silica; mobile phase,
Fig. 1 Analytical procedure for urinary dialkylphosphates
$1 \mathrm{~mL}$ urine

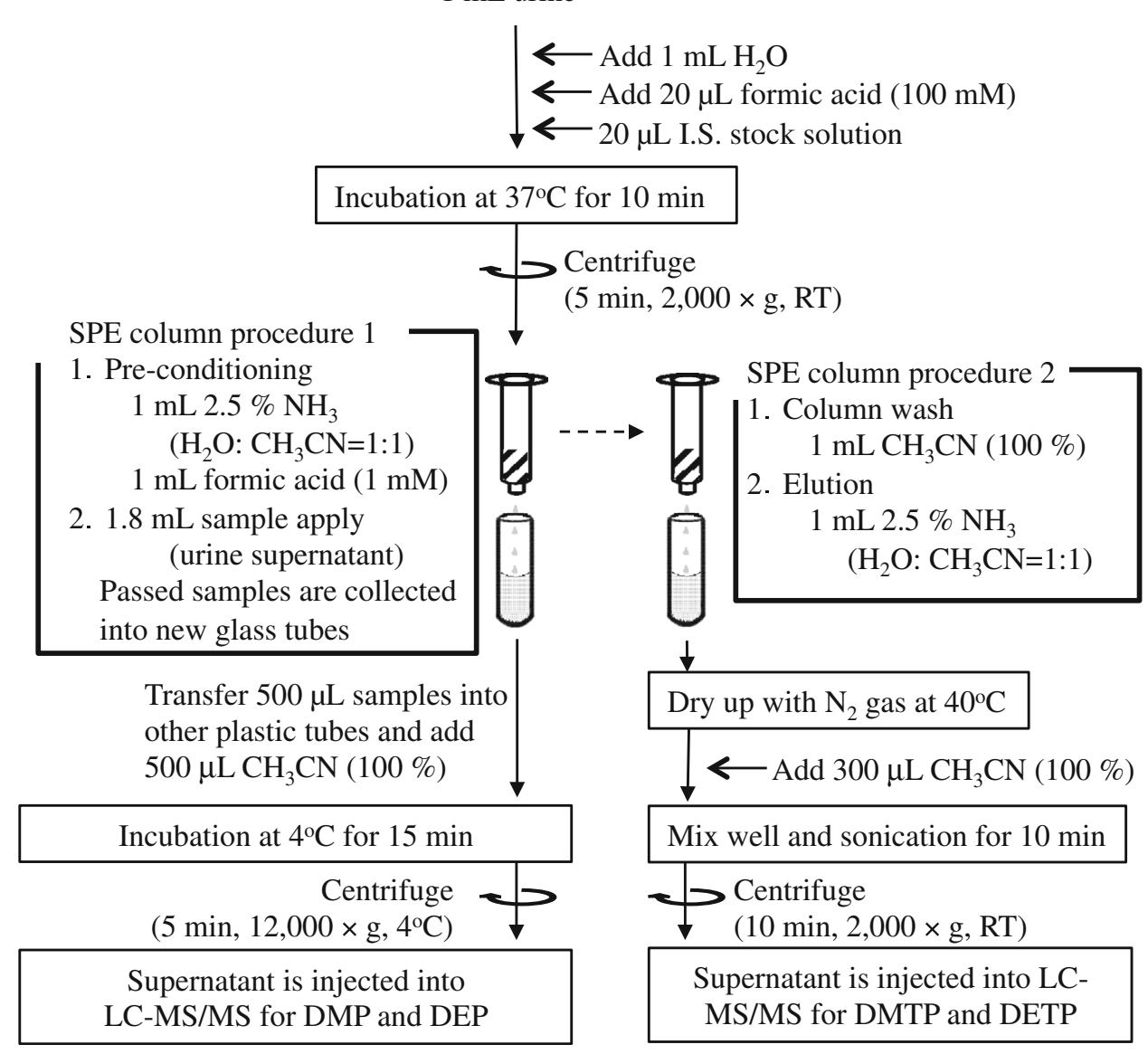


Table 2 Compound-specific mass spectrometer settings
$C$ confirmation ion,

$Q$ quantification ion

a Total of $\mathrm{Q}$ and $\mathrm{C}$ were used for DMTP quantification due to its low sensitivity

\begin{tabular}{lclllll}
\hline Compounds & $\begin{array}{l}\text { Fragementor } \\
(\mathrm{V})\end{array}$ & $\begin{array}{l}\text { Precursor ion } \\
(\mathrm{m} / \mathrm{z})\end{array}$ & $\begin{array}{l}\text { Product ion } \\
(\mathrm{m} / \mathrm{z})\end{array}$ & $\begin{array}{l}\text { Collision } \\
\text { energy }(\mathrm{eV})\end{array}$ & Polarity & $\begin{array}{l}\text { Retention time } \\
(\mathrm{min})\end{array}$ \\
\hline DMP-d $_{6}$ & 90 & 133 & 115 & 18 & Positive & 6.48 \\
DMP & 90 & 127 & $109(\mathrm{Q})$ & 20 & Positive & 6.48 \\
& & & $95(\mathrm{C})$ & 20 & & \\
DMTP-d $_{6}$ & 90 & 147 & 129 & 14 & Negative & 6.54 \\
DMTP & 90 & 141 & $126(\mathrm{Q})^{\mathrm{a}}$ & 13 & Negative & 6.54 \\
& & & $96(\mathrm{C})$ & 21 & & \\
DEP-d ${ }_{10}$ & 80 & 165 & 101 & 16 & Positive & 6.53 \\
DEP $^{20}$ & 80 & 155 & $127(\mathrm{Q})$ & 10 & Positive & 6.53 \\
& & & $99(\mathrm{C})$ & 10 & Negative & 6.89 \\
DETP-d & 100 & 179 & 95 & 20 & Negative & 6.89 \\
DETP & 90 & 169 & $95(\mathrm{Q})$ & 17 & & \\
& & & $141(\mathrm{C})$ & 9 & & \\
\hline
\end{tabular}

$1 \mathrm{mmol} / \mathrm{L}$ formic acid and acetonitrile mixture (20:80, v/v) (A), and $10 \mathrm{mmol} / \mathrm{L}$ formic acid solution containing $10 \mathrm{mmol} / \mathrm{L}$ ammonium formate and acetonitrile mixture $(20: 80, v / v)(B)$; gradient condition of mobile phase B, $0 \%$ (for $1 \mathrm{~min}$ ) $-14 \% / \mathrm{min}-70 \%$ (for $2 \mathrm{~min}$ ) $-70 \% / \mathrm{min}-0 \%$ (for $3 \mathrm{~min}$ ); total flow rate of mobile phase $\mathrm{A}$ and $\mathrm{B}$, $0.2 \mathrm{~mL} / \mathrm{min}$; total run time per sample, $12 \mathrm{~min}$. All chromatographic solvents were degassed in a sonication bath for $20 \mathrm{~min}$. The injection volume was $20 \mu \mathrm{L}$.

DAP detections were achieved by a triple quadrupole mass spectrometer equipped with an electro spray ionization (ESI) source using multiple reaction monitoring (MRM). Nebulizer gas (nitrogen) pressure was set at $35 \mathrm{psi}$ with a source temperature of $325{ }^{\circ} \mathrm{C}$, and the gas flow rate was $10 \mathrm{~L} / \mathrm{min}$. Capillary voltage was $4,000 \mathrm{~V}$ (positive mode for DMP and DEP, negative mode for DMTP and DETP). High-purity nitrogen gas was used as collision cell gas. Table 2 shows the optimized MRM parameters and retention times for OP metabolites and their I.S. The raw chromatograph and mass spectrogram data were processed with MassHunter Software Workstation (Agilent).

\section{Assay validation}

The intra- and inter-day precisions of our method were evaluated by parallel analytical runs performed on the same day or on seven consecutive days. To determine and calculate absolute recoveries, we spiked DAPs at two different stages in the DAP measurement procedure; i.e., in the beginning of the extraction procedure (urine sample) and prior to the injection procedure into LC-MS/MS. We compared the I.S. ratios obtained at these two stages. Matrix-matched calibration curves were represented by the analyte/I.S. peaks area ratio versus the concentrations of the calibration samples ranging from 1 to $200 \mu \mathrm{g} / \mathrm{L}$ for DMP and DEP, and from 0.1 to $200 \mu \mathrm{g} / \mathrm{L}$ for DEP and
DETP (each curve was drawn using five different concentrations). These DAP concentration ranges were determined based on the urinary DAP concentration ranges observed in Japanese people [6]. Indeed, these calibration curves are applicable to more than about $95 \%$ of the Japanese general population [6]. The limits of detection (LOD) and limits of quantitation (LOQ) were calculated on the assumption of signal-to-noise ratios of 3 and 10, respectively. Dilution validation was evaluated using urinary samples at high DAP concentrations obtained from occupationally exposed workers. The urinary DAP concentrations were as follows: $216 \mu \mathrm{g} / \mathrm{L}$ for DMP, $110 \mu \mathrm{g} / \mathrm{L}$ for DMTP and $76 \mu \mathrm{g} / \mathrm{L}$ for DEP. Dilution validation of DETP could not be evaluated due to its relatively low concentration (maximum DETP concentration was $2.6 \mu \mathrm{g} /$ $\mathrm{L}$ among available urine samples in this study).

Sample stability

Stability of the DAPs in human urine was determined using DAP-spiked urine samples at two concentrations (20 and $200 \mu \mathrm{g} / \mathrm{L}$ for DMP, 2 and $20 \mu \mathrm{g} / \mathrm{L}$ for DMTP, DEP and DETP). Urine samples in screw-top glass tubes were incubated at 4 or $37{ }^{\circ} \mathrm{C}$ for $24 \mathrm{~h}$, and then urinary DAPs were measured. DAP peak areas of urine incubated for $24 \mathrm{~h}$ were compared with those of urine right before incubation. For the freeze and thaw stability test, urine samples were stored at $-80{ }^{\circ} \mathrm{C}$ for $24 \mathrm{~h}$ and thawed with tap water for $10 \mathrm{~min}$. After incubation at room temperature for $1 \mathrm{~h}$, the urine samples were stored at $-80{ }^{\circ} \mathrm{C}$ for $24 \mathrm{~h}$ again. I.S. ratios for DAP peak areas obtained from freeze and thaw-cycled urine were compared with those of urine which was not frozen at any point. Stability of prepared samples, which were injected into the LC, was also tested at a concentration of $5 \mu \mathrm{g} / \mathrm{L}$ DAPs. DAPs in prepared samples were analyzed immediately, and stored on the LC 
auto sampler at $4{ }^{\circ} \mathrm{C}$ for $24 \mathrm{~h}$ or 5 days. DAP stability was assessed by comparing peak areas of DAP samples stored for $24 \mathrm{~h}$ or 5 days with those samples stored for $0 \mathrm{~h}$.

Cross-validation of DAP analysis between previously reported method and present method

Thirty-five urine samples, which were obtained from occupationally OP-exposed group (pest control operators), have been measured with both our previous method [17] and the present method, because we have to evaluate the analytical comparability of these data. The characteristics of pest control operators were mentioned in our previous paper [6]. Pearson's correlation coefficient and intraclass correlation coefficient (two-way random model) (ICC) statistics were calculated after logarithmic transformation of urinary DAP concentrations. Statistical analysis was performed with SPSS $^{\circledR} 19.0$ (SPSS Inc., Chicago, IL, USA).

Urinary DAPs in young Japanese children aged 3 years

The study population consisted of 3-year-old children who lived in Inuyama and Okazaki City, Aichi Prefecture (central area of Japan) between August 2012 and February 2013. Informed consent forms and questionnaires were mailed to 708 families who had 3-year-old children scheduled to participate in a health checkup for 3-year-olds conducted by the city governments. Prior to enrollment in the study, parents of each subjects signed an informed consent form permitting the use of personal information and urine for research purposes. Four hundred and four subjects were recruited for this study, and their questionnaires and urine samples were obtained. Collected urine samples were transported at $4{ }^{\circ} \mathrm{C}$ to our laboratory, and then stored at $-80{ }^{\circ} \mathrm{C}$ until DAP analyses. Eventually, 225 morning urine samples were obtained from the subjects, each donating more than $4 \mathrm{~mL}$ of urine, and they were applied for our methods. DAP concentrations of these samples may well be representative data of children who live in the area. The Ethics Committee of Nagoya University Graduate School of Medicine approved the study protocol, along with the Helsinki Declaration. Urinary creatinine concentrations were measured according to the previously reported method using LC [22].

\section{Results}

Optimization of sample preparation and LC-MS/MS conditions

SPE procedure for DAP extraction was adopted in this study to assure easy handling and high purification. As shown in Fig. 1, we devised a new method that allows DMP and DEP in urine to pass through weak anion exchange SPE columns. Mass chromatogram of pooled urine spiked with DAPs at concentration ranges from 0 to $200 \mu \mathrm{g} / \mathrm{L}$ is shown in Fig. 2 .

Assay validation

The accuracy, precision, and linearity parameters are summarized in Table 3. The DMP recoveries by this method yielded 95 and $100 \%$ concentrations in 1 and $5 \mu \mathrm{g} / \mathrm{L}$ of urine, respectively. For the within-run precision, the percent of relative standard deviation (\%RSD) ranged from 2.7 to $10.7 \%$. For the between-run precision, the $\%$ RSD was between 4.3 and $9.6 \%$. These precision data improved considerably in comparison with our previous method [17]. Reproducibility deteriorated when the I.S was not used. Calibration curves were constructed by plotting the peak area ratio of DAPs to I.S. ( $y$ axis) versus the concentration of DAPs ( $x$ axis). The regression equations were $y=0.446 x-0.84$ for DMP, $y=0.024 x+0.15$ for DMTP, $y=0.073 x-0.16$ for DEP, and $y=0.060 x$ +0.035 for DETP. A good dilution validation was confirmed when serially diluted urine samples were analyzed between the dilution ratio and analyte/I.S ratio $\left(r^{2}>0.9997\right.$ for DMP, DMTP and DEP), suggesting that urine matrix had no effect on ionization of DMP, DMTP and DEP.

\section{Sample stability}

The stabilities of DAPs in urine and prepared samples were assessed under typical storage/handling conditions (Table 4). Incubation of urine samples at 4 or $37^{\circ} \mathrm{C}$ caused negligible changes in DAP peak areas (93-112\% for urinary DAPs). DAP peak-areas in four-time freeze and thawcycled urine were approximately at the same level as those in fresh urine samples (94-111\% for urinary DAPs).

Comparison of DAP concentrations measured by two methods

We evaluated whether there were comparability of DAP data obtained from previous method (GC-MS) and the present method (LC-MS/MS). Geometric means of urinary DAP concentrations in pest control operators measured by the present method (LC-MS/MS) were $8.9 \mu \mathrm{g} / \mathrm{L}$ (max. $256.4 \mu \mathrm{g} / \mathrm{L}$ ) for $\mathrm{DMP}, 3.5 \mu \mathrm{g} / \mathrm{L}(\max .81 .9 \mu \mathrm{g} / \mathrm{L})$ for DMTP, $2.9 \mu \mathrm{g} / \mathrm{L}(\max .88 .2 \mu \mathrm{g} / \mathrm{L}$ ) for DEP and $0.4 \mu \mathrm{g} / \mathrm{L}$ (max. $5.7 \mu \mathrm{g} / \mathrm{L}$ ) for DETP. Pearson's correlation coefficient and ICC were as follows: DMP, 0.829 and 0.747; DMTP, 0.843 and 0.740; DEP, 0.766 and 0.616; DETP, 0.831 and 0.532 . 
Fig. 2 Mass chromatogram of dialkylphosphates at concentration range from 0 to $200 \mu \mathrm{g} / \mathrm{L}$
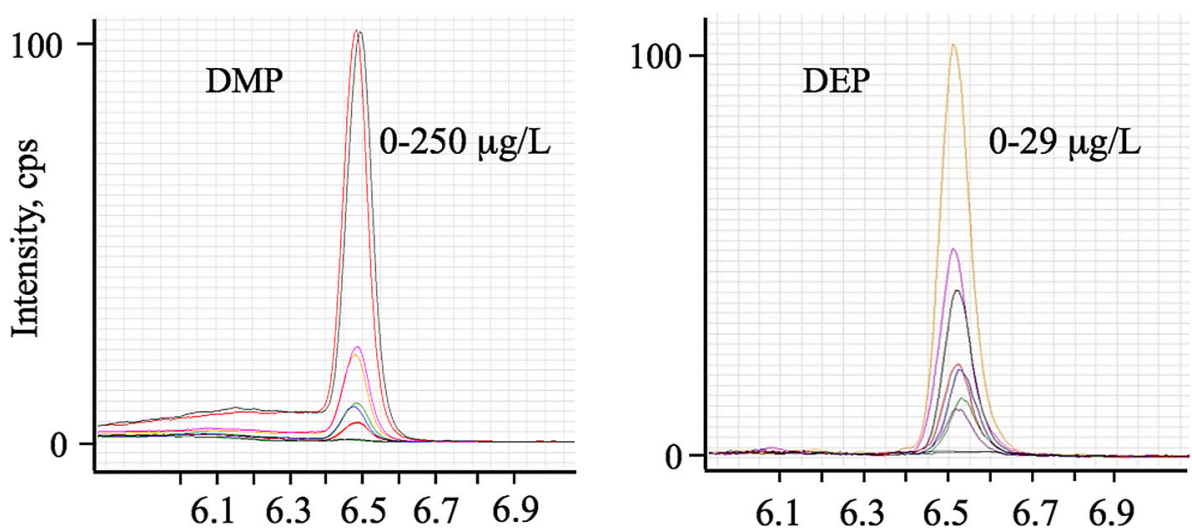

$\begin{array}{lllll}6.1 & 6.3 & 6.5 & 6.7 & 6.9\end{array}$
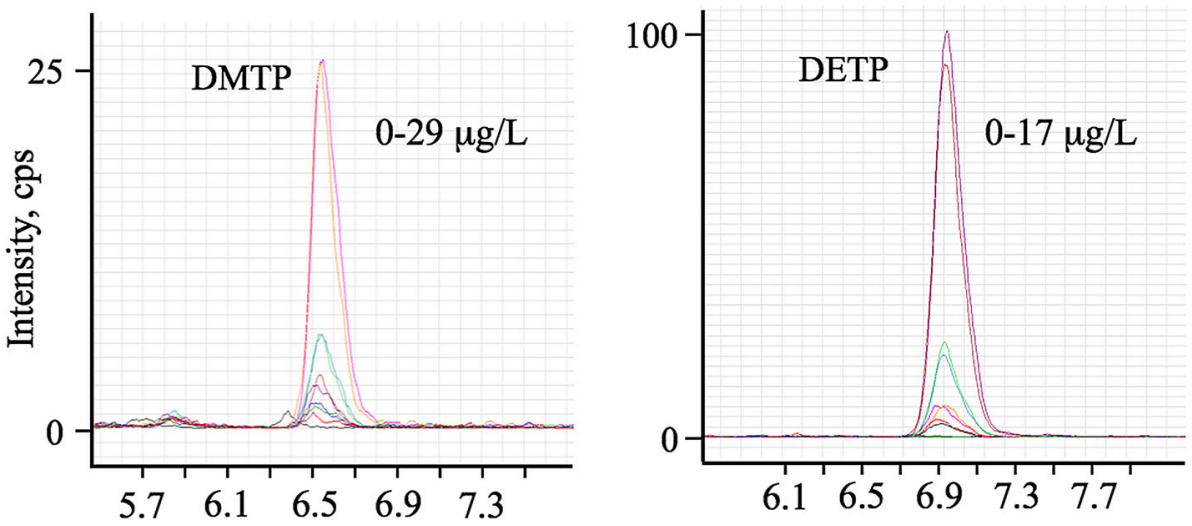

Table 3 Accuracy, precision, LOD and LOQ data of analytical procedure

\begin{tabular}{|c|c|c|c|c|c|c|}
\hline & $\begin{array}{l}\text { Concentration } \\
(\mu \mathrm{g} / \mathrm{L})\end{array}$ & $n$ & DMP & DMTP & DEP & DETP \\
\hline \multirow{6}{*}{$\begin{array}{l}\text { Within-run } \\
\text { precision } \\
(\% \text { RSD) }\end{array}$} & 1 & 4 & & & 10.3 & 6.4 \\
\hline & 2 & 4 & 3.1 & 9.8 & 10.7 & 3.4 \\
\hline & 5 & 4 & 3.1 & 2.7 & 3.9 & 4.5 \\
\hline & 10 & 4 & 3.6 & 5.8 & & \\
\hline & 20 & 4 & & & 5.5 & 3.2 \\
\hline & 100 & 4 & 6.7 & 3.6 & & \\
\hline \multirow{2}{*}{$\begin{array}{l}\text { Mean } \\
\text { recovery }^{\mathrm{a}}\end{array}$} & 1 & 2 & 95 & 64 & 81 & 101 \\
\hline & 5 & 2 & 100 & 105 & 82 & 93 \\
\hline \multirow{2}{*}{$\begin{array}{l}\text { Between-run } \\
\text { precision } \\
(\% \mathrm{RSD})\end{array}$} & 1 & 7 & 6.9 & 7.7 & 9.6 & 7.6 \\
\hline & 10 & 7 & 9.0 & 4.3 & 7.5 & 7.8 \\
\hline $\begin{array}{l}R^{2} \text { of } \\
\text { calibration } \\
\text { line }\end{array}$ & & & 0.999 & 0.998 & 0.997 & 0.999 \\
\hline $\begin{array}{l}\mathrm{LOD}(\mu \mathrm{g} / \mathrm{L}) \\
\quad(\mathrm{S} / \mathrm{N}=3)\end{array}$ & & & 0.4 & 0.4 & 0.2 & 0.1 \\
\hline $\begin{array}{l}\mathrm{LOQ}(\mu \mathrm{g} / \mathrm{L}) \\
\quad(\mathrm{S} / \mathrm{N}=10)\end{array}$ & & & 1.2 & 1.2 & 0.6 & 0.3 \\
\hline
\end{tabular}

Table 4 Storage stability of urinary DAPs

\begin{tabular}{|c|c|c|c|c|c|}
\hline \multirow[t]{2}{*}{ Condition } & \multirow{2}{*}{$\begin{array}{l}\text { Concentration } \\
\text { ( } \mu \mathrm{g} / \mathrm{L} \text { urine) }\end{array}$} & \multicolumn{4}{|c|}{$\%$ RSD } \\
\hline & & DMP & DMTP & DEP & DETP \\
\hline \multicolumn{6}{|l|}{ Urine sample } \\
\hline \multirow[t]{3}{*}{ Stored at $4{ }^{\circ} \mathrm{C}$} & 2 & & 111 & 94 & 112 \\
\hline & 20 & 93 & 101 & 102 & 93 \\
\hline & 200 & 99 & & & \\
\hline \multirow[t]{3}{*}{ Stored at $37^{\circ} \mathrm{C}$} & 2 & & 106 & 109 & 108 \\
\hline & 20 & 97 & 104 & 104 & 102 \\
\hline & 200 & 100 & & & \\
\hline \multirow{3}{*}{$\begin{array}{l}\text { After four times } \\
\text { freeze-thaw } \\
\text { cycles }\end{array}$} & 2 & & 97 & 94 & 96 \\
\hline & 20 & 95 & 100 & 104 & 103 \\
\hline & 200 & 111 & & & \\
\hline \multicolumn{6}{|l|}{ Prepared sample } \\
\hline $\begin{array}{l}\text { Stored at } 4{ }^{\circ} \mathrm{C} \\
\text { for } 1 \text { day }\end{array}$ & 5 & 93 & 97 & 96 & 95 \\
\hline $\begin{array}{l}\text { Stored at } 4{ }^{\circ} \mathrm{C} \\
\text { for } 5 \text { days }\end{array}$ & 5 & 90 & 109 & 104 & 102 \\
\hline
\end{tabular}

$R S D$ relative standard deviation

Application for environmental OP exposures

Another purpose of this study is to evaluate DAP concentrations in Japanese children. The detection rates of 
Table 5 Urinary DAP concentrations reported in previous papers

\begin{tabular}{|c|c|c|c|c|c|c|c|c|c|c|c|}
\hline \multirow{2}{*}{$\begin{array}{l}\text { Author } \\
\text { Sampling country }\end{array}$} & \multirow{2}{*}{$\begin{array}{l}\text { Study } \\
\text { population } \\
\text { (years) }\end{array}$} & \multirow[t]{2}{*}{ Units } & \multirow{2}{*}{$\begin{array}{l}\text { Sample } \\
\text { size }\end{array}$} & \multicolumn{4}{|l|}{ GM } & \multicolumn{4}{|c|}{95 percentile } \\
\hline & & & & DMP & DMTP & DEP & DETP & DMP & DMTP & DEP & DETP \\
\hline \multirow[t]{2}{*}{ Barr et al. [7], USA (NHANES 2003-2004) } & \multirow[t]{2}{*}{$6-11$} & $\mu \mathrm{g} / \mathrm{L}$ & 296 & $\mathrm{NC}$ & 2.8 & $\mathrm{NC}$ & $\mathrm{NC}$ & 16.2 & 30.9 & 16.1 & 2.2 \\
\hline & & $\mu \mathrm{g} / \mathrm{g}$ cre & -310 & $\mathrm{NC}$ & 3.4 & $\mathrm{NC}$ & $\mathrm{NC}$ & 19.6 & 36.1 & 16.1 & 2.7 \\
\hline \multirow[t]{2}{*}{ Becker et al. [8], Germany } & \multirow[t]{2}{*}{$2-17$} & $\mu \mathrm{g} / \mathrm{L}$ & 363 & 13.5 & 8.2 & 3.3 & 1.1 & 118 & 124 & 20.0 & 11.0 \\
\hline & & $\mu \mathrm{g} / \mathrm{g}$ cre & & 10.7 & 6.5 & 2.6 & 0.9 & 95.8 & 109 & 14.1 & - \\
\hline \multirow{2}{*}{$\begin{array}{l}\text { Babina et al. [9] }{ }^{\mathrm{a}} \text {, Australia (Periurban } \\
\text { area) }\end{array}$} & \multirow[t]{2}{*}{$2.5-6$} & $\mu \mathrm{g} / \mathrm{L}$ & 111 & - & - & - & - & - & - & - & - \\
\hline & & $\mu \mathrm{g} / \mathrm{g}$ cre & & - & 24.8 & 15.4 & 7.9 & - & 698 & 387 & 114 \\
\hline \multirow[t]{2}{*}{ Present study, Japan } & \multirow[t]{2}{*}{3} & $\mu \mathrm{g} / \mathrm{L}$ & 225 & 14.4 & 5.3 & 5.5 & 0.6 & 59.0 & 65.3 & 25.2 & 5.0 \\
\hline & & $\mu \mathrm{g} / \mathrm{g}$ cre & & 21.0 & 7.8 & 8.0 & 0.9 & 68.0 & 81.7 & 33.1 & 6.3 \\
\hline
\end{tabular}

$N C$ not calculated, NHANES National Health and Nutrition Examination Survey, GM geometric mean, cre creatinine

${ }^{\text {a }}$ Median values were represented instead of GM

urinary DAPs were $80-100 \%$. The geometric means and 95 percentile were shown in Table 5. This implies that our method can be applied to the biomonitoring of urinary DAPs of Japanese children who are environmentally exposed to OP. We confirmed that the distribution of concentrations of urinary DAPs was normalized by logarithmic transformation.

\section{Discussion}

First of all, an optimum sample preparation method was sought so as to yield a sensitive determination. Dulaurent et al. [19] adopted liquid-liquid DAP extraction using diethylether and ethylacetate, and obtained low recoveries (13\% for DMP and $25 \%$ for DMTP) at a DAP concentration of $2 \mu \mathrm{g} / \mathrm{L}$. Odetokun et al. [20] selected weak anion exchange SPE columns (Strata X-AW, Phenomenex Inc; Torrance, CA, USA) as the DAP extraction column with a DMP recovery rate of only $40 \%$. These low recoveries of DMP were due in part to the high polarity and weak positive charge of DMP compared with other DAPs. Therefore, the high absolute recovery of DAPs in our method can be highlighted as significant. Although recovery rate of DEP at concentration of $1 \mu \mathrm{g} / \mathrm{L}$ was relatively low, the extent of recoveries of analytes was reproducible.

The analytical separation of the four analytes in this study was performed using a ODS column consisting of C18, weak anion, and weak cation ligands. This hybrid column allowed DAP separation from urine matrix without addition of TEA as an ion pair reagent. Moreover, injection of a large volume of prepared samples $(20 \mu \mathrm{L})$ into the $\mathrm{LC}$ contributed to highly sensitive DAP detection without TEA addition as an accelerating reagent for DAP ionization. This may have been caused by the condensation of DAPs at the forefront of the analytical column after the sample injection into the LC, because the weak anion exchange ligand can hold DAPs tightly under a condition of abundant mobile phase A. The retention times of DAPs were similar to each other. We have confirmed that the concentration of one DAP component was not affected by that of the other components.

Although dibuthylphosphate was used as the I.S. in our previous studies using GC-MS [11], the present method did not show good within-run precision when using dibuthylphosphate (\%RSD $>15 \%$ ), suggesting that deuteriumlabeled DAPs are indispensable when using LC-MS/MS to obtain ideal within-run precision.

Odetokiun et al. [20] and we [17] have reported a DAP measurement method with sufficient LODs of 0.5 and $0.3 \mu \mathrm{g} / \mathrm{L}$ for DMP, 0.07 and $0.1 \mu \mathrm{g} / \mathrm{L}$ for DMTP, 0.05 and $0.1 \mu \mathrm{g} / \mathrm{L}$ for DEP and 0.11 and $0.1 \mu \mathrm{g} / \mathrm{L}$ for DETP. Although the LODs for DAPs in this study are not lower than those in Odetokiun's study, the LODs in ours are sufficiently low for measurement of each urinary DAP from the Japanese general population [6]. It can be presumed that the high DAP recoveries and the large volume sample injection into the LC-MS/MS achieved highly sensitive analyses without TEA.

The results of sample stability examination corroborate that the stability of urinary DAPs is unaffected by the usual collecting conditions in the field survey. Further studies concerning DAP stability using urine samples obtained from individuals under various medical conditions are needed, because it is not clear how the variability of urine components such as oxidants and drugs in urine affects DAP stability.

We previously demonstrated that the geometric means of summertime urinary DMP, DMTP, DEP and DETP concentrations in 164 Japanese adults $(42 \pm 10$ years, mean $\pm \mathrm{SD}$ ) were $10.3,5.1,1.3$ and $0.4 \mu \mathrm{g} / \mathrm{L}$, respectively 
(7.0, 3.4, 0.8 and $0.3 \mu \mathrm{g} / \mathrm{g}$ creatinine, respectively) [6]. These data were obtained using our previous method using GC-MS [17]. From a statistical viewpoint [23], more than 0.81 of ICC are categorized as 'almost perfect'. The ICC level $0.61-0.81$ and $0.41-0.60$ are categorized as 'substantial' and 'moderate', respectively. Given the high Pearson's correlation and ICC, the DAP concentrations measured by our previous method [17] and present method may be reliably comparable, except for DETP due to its low concentration. To ameliorate the ICC of DETP, we might have to adopt duplicate or triplicate assay.

Although urinary DAP concentrations in Japanese children are seemingly higher than those in Japanese adults, careful considerations should be made about the differences in physiologic characteristics between adults and children, such as OP metabolizing enzyme activity, urine volume, and urinary creatinine excretion level. In an international comparison of the geometric mean or median level of urinary DAP concentrations, it is likely that the DMP concentration in our data was approximately the same or higher than that of US (6-11 years of age) [7], German (2-17 years of age) [8] and Australian (2.5-6 years of age) [9] children (Table 5). Urine volume and creatinine excretion in urine increase with increasing age toward adults. An earlier study by Babina et al. [9] has suggested that urinary DAP concentrations in urban area children were higher than those in rural area children. Moreover, we reported that total DAP concentrations in summer were higher than those in winter [6]. Therefore, it is difficult at present to conclude that higher OP exposures have occurred in Japanese children than in other countries.

A further study of biological monitoring of urinary DAPs from a large number of subjects would be needed to evaluate the adverse effects of OP exposure. Since our simple and sensitive method for DAP determination can also achieve a high-throughput measurement without labor-intensive operation, it can be applied to routine biological monitoring of urinary DAPs, not only in occupational health studies but also in epidemiological studies.

In conclusion, a sensitive and reliable LC-MS/MS method with SPE sample preparation for the determination of urinary DAPs was developed. The main strengths of the present study are its development of a TEA-free sensitive determination of urinary DAPs, and its first report about urinary DAP concentrations in Japanese children. This study is a major step toward the human risk assessment of OP exposures.

Acknowledgments This work was supported in part by a Grant-inAid for Scientific Research (23689034 and 26460799) from the Japan Society for the Promotion of Science.

Conflict of interest The authors declare that they have no conflict of interest.

\section{References}

1. Bardin PG, Eeden SF, Moolman JA, Foden AP, Joubert JR. Organophosphate and carbamate poisoning. Arch Intern Med. 1994;154:1433-41.

2. Rohlman DS, Anger WK, Lein PJ. Correlating neurobehavioral performance with biomarkers of organophosphorous pesticide exposure. Neurotoxicology. 2011;32:268-76.

3. Bouchard MF, Bellinger DC, Wright RO, Weisskopf MG. Attention-deficit/hyperactivity disorder and urinary metabolites of organophosphate pesticides. Pediatrics. 2010;125:1270-7.

4. Lacasaña M, López-Flores I, Rodríguez-Barranco M, AguilarGarduño C, Blanco-Muñoz J, Pérez-Méndez O, Gamboa R, Bassol S, Cebrian ME. Association between organophosphate pesticides exposure and thyroid hormones in floriculture workers. Toxicol Appl Pharmacol. 2010;243:19-26.

5. Bouchard MF, Chevrier J, Harley KG, Kogut K, Vedar M, Calderon N, et al. Prenatal exposure to organophosphate pesticides and IQ in 7-year-old children. Environ Health Perspect. 2011;19:1189-95.

6. Ueyama J, Saito I, Kondo T, Taki T, Kimata A, Saito S, et al. Urinary concentrations of organophosphorus insecticide metabolites in Japanese workers. Chemosphere. 2012;87:1403-9.

7. Barr DB, Wong LY, Bravo R, Weerasekera G, Odetokun M, Restrepo P, et al. Urinary concentrations of dialkylphosphate metabolites of organophosphorus pesticides: National Health and Nutrition Examination Survey 1999-2004. Int J Environ Res Public Health. 2011;8:3063-98.

8. Becker K, Seiwert M, Angerer J, Kolossa-Gehring M, Hoppe HW, Ball M, et al. GerES IV pilot study: assessment of the exposure of German children to organophosphorus and pyrethroid pesticides. Int J Hyg Environ Health. 2006;209:221-33.

9. Babina K, Dollard M, Pilotto L, Edwards JW. Environmental exposure to organophosphorus and pyrethroid pesticides in South Australian preschool children: a cross sectional study. Environ Int. 2012;48:109-20.

10. Nutley BP, Cocker J. Biological monitoring of workers occupationally exposed to organophosphorus pesticides. Pest Sci. 1993;38:315-22.

11. Aprea C, Sciarra G, Lunghini L. Analytical method for the determination of urinary alkylphosphates in subjects occupationally exposed to organophosphorus pesticides and in the general population. J Anal Toxicol. 1996;20:559-63.

12. Moate TF, Lu C, Fenske RA, Hahne RM, Kalman DA. Improved cleanup and determination of dialkyl phosphates in the urine of children exposed to organophosphorus insecticides. J Anal Toxicol. 1999;23:230-6.

13. Hardt J, Angerer J. Determination of dialkyl phosphates in human urine using gas chromatography-mass spectrometry. J Anal Toxicol. 2000;24:678-84.

14. Oglobline AN, Elimelakh H, Tattam B, Geyer R, O'Donnell GE, Holder G. Negative ion chemical ionization GC/MS-MS analysis of dialkylphosphate metabolites of organophosphate pesticides in urine of non-occupationally exposed subjects. Analyst. 2001;126:1037-41.

15. Lin WC, Kuei CH, Wu HC, Yang CC, Chang HY. Method for the determination of dialkyl phosphates in urine by strong anion exchange disk extraction and in-vial derivatization. J Anal Toxicol. 2002;26:176-80.

16. Bravo R, Driskell WJ, Whitehead RD Jr, Needham LL, Barr DB. Quantitation of dialkyl phosphate metabolites of organophosphate pesticides in human urine using GC-MS-MS with isotopic internal standards. J Anal Toxicol. 2002;26:245-52.

17. Ueyama J, Saito I, Kamijima M, Nakajima T, Gotoh M, Suzuki $\mathrm{T}$, et al. Simultaneous determination of urinary dialkylphosphate 
metabolites of organophosphorus pesticides using gas chromatography-mass spectrometry. J Chromatogr B. 2006;832:58-66.

18. De Alwis GKH, Needham LL, Barr DB. Measurement of human urinary organophosphate pesticide metabolites by automated solid-phase extraction derivation and gas chromatography-tandem mass spectrometry. J Chromatogr B Analyt Technol Biomed Life Sci. 2006;843:34-41.

19. Dulaurent S, Saint-Marcoux F, Marquet P, Lachâtre G. Simultaneous determination of six dialkylphosphates in urine by liquid chromatography tandem mass spectrometry. J Chromatogr B Anal Technol Biomed Life Sci. 2006;831:223-9.

20. Odetokun MS, Montesano MA, Weerasekera G, Whitehead RD Jr, Needham LL, Barr DB. Quantification of dialkylphosphate metabolites of organophosphorus insecticides in human urine using 96-well plate sample preparation and high-performance liquid chromatography-electrospray ionization-tandem mass spectrometry. J Chromatogr B Analyt Technol Biomed Life Sci. 2010;878:2567-74.

21. Rütters H, Möhring T, Rullkötter J, Griep-Raming J, Metzger JO. The persistent memory effect of triethylamine in the analysis of phospholipids by liquid chromatography/mass spectrometry. Rapid Commun Mass Spectrom. 2000;14:122-3.

22. Guy JM, Legg EF. An improved cation exchange HPLC method for the measurement of serum creatinine. Ann Clin Biochem. 1990;27:223-6.

23. Landis JR, Koch GG. The measurement of observer agreement for categorical data. Biometrics. 1977;33:159-74. 